\title{
Neuroanatomy of Two Species of Genus Myliobatis (Chondrichthyes: Myliobatoidea)
}

\author{
Neuroanatomía de Dos Especies del Género Myliobatis (Chondrichthyes: Myliobatoidea)
}

Héctor Marcos Montes-Domínguez ${ }^{1,3}$; Luis Amado AyalaPérez²; Manuel Arnoldo

Castillo Rivera ${ }^{4}$; Mónica González Isáis ${ }^{3}$ \& Víctor Hugo Reynoso ${ }^{5}$

\begin{abstract}
MONTES-DOMÍNGUEZ, H. M.; AYALA-PÉREZ, L. A.; CASTILLO-RIVERA, M. A.; GONZÁLEZ-ISÁIS, M. \& REYNOSO,
V. H. Neuroanatomy of two species of genus Myliobatis (Chondrichthyes: Myliobatoidea). Int. J. Morphol., 38(2):499-504, 2020.

SUMMARY: Several studies on the elasmobranchs neuroanatomy have shown that their brain is more complex than previously thought, and had significant intra and interspecific variations. The objective of this work was conducting a comparative encephalic neuroanatomy study of two species of genus Myliobatis. In total, 16 organisms of genera Myliobatis californica and Myliobatis longirostris, collected in the coasts of Kino Bay, Sonora, Mexico, were used. In Myliobatis, the brain has a long telencephalon and the posterior central nucleus is poorly developed. Their cerebellum is asymmetric, has several sulci, most of which are transversally oriented, with four lobes (anterior, medium and two posterior), a condition which has not been reported for any other species. It was observed that, despite the morphology of $M$. californica and M. longirostris is similar, there are some significant differences. Both species have moderate foliation, but $M$. californica has more sulci. In the diencephalon of $M$. californica, it was observed that the lobes of the infundibulum are oval-shaped and separated, while in M. longirostris, such lobes are rounded and near the medium line. It has to be highlighted that Myliobatis belongs to the most derived batoid group; nevertheless, its brain is considerably less complex, as compared to what has been reported for the most derived milyobatoids species.
\end{abstract}

KEY WORDS: Elasmobranchii; Myliobatis; Gross brain; Telencephalon; Cerebellum.

\section{INTRODUCTION}

Batoids or rays, are a specialized group, derived from neoselachii sharks, and distribute in marine, estuaries, rivers and freshwater systems. They include over 630 species in four orders, 17 families and 83 genera, which is over one-half of all living elasmobranchii known (Nelson et al., 2016). The order Myliobatiformes makes up $35 \%$ of all batoid species (Compagno, 1990), and includes the family Myliobatidae, which, according to White \& Last (2016) is represented by two genera (Aetomylaeus and Myliobatis), and 18 species. Both genera are characterized by having a short, rounded rostral lobe, and rhombic disc (Nelson et al.; White \& Last).

Works conducted on the batoids neuroanatomy have revealed a significant variation among different groups, particularly in the telencephalon and cerebellum structures (Smeets, 1998; Hoffman, 1999; Ari, 2011). It has also been shown that some structures have differences during the development of organisms, including the optic lobes, the mesencephalon (Lisney \& Collin, 2006; Lisney et al., 2007, 2017), and the cerebellum foliation level (Ari). However, only a few works have considered species of family Myliobatidae. Northcutt (1978) and Smeets, published a diagram of $M$. californica in dorsal view. All other neuroanatomy works have focused on different batoid groups (Northcutt, 1977, 1978, 1989; Smeets; Hoffman), including Urobatis jamaicensis (Walker \& Sherman, 2001), Diplobatis ommata (Montes Domínguez et al., 2014), potamotrygonids (Fontanelle \& Carvalho, 2016), Gymnura micrura (Kobelkowsky, 2017), and mobulids (Ari). The objective of this work was conducting a comparative anatomy study of the external morphology of the encephalon in two species of the genus Myliobatis.

\footnotetext{
${ }^{1}$ Doctorado en Ciencias Biológicas y de la Salud, Universidad Autónoma Metropolitana, Unidad Xochimilco, México.

${ }^{2}$ Universidad Autónoma Metropolitana, Unidad Xochimilco, México.

${ }^{3}$ Facultad de Estudios Superiores Iztacala, UNAM, México.

${ }^{4}$ Universidad Autónoma Metropolitana, Unidad Iztapalapa, México.

${ }^{5}$ Instituto de Biología, Universidad Nacional Autónoma de México, México.
} 


\section{MATERIAL AND METHOD}

Ten specimens of Myliobatis californica (Gill, 1865), and six of Myliobatis longirostris (Applegate \& Fitch, 1964), all sexually mature, were used. Animals were collected in the coast of Kino Bay, Son., Mexico. In the field, the brain was exposed and fixed with $4 \%$ saline formaline. In the lab, each cranium was processed with the conventional brain extraction technique. In the dissection, the dorsal, frontal, lateral, and ventral regions of the brain were exposed, which were later described. Subsequently, the cerebellum, the posterior choroid plexus and the auricles upper lip were removed, to observe structures underneath. Terminology used was the same used by Northcutt $(1977,1978,1989)$, Smeets and Fontanelle \& Carvalho.
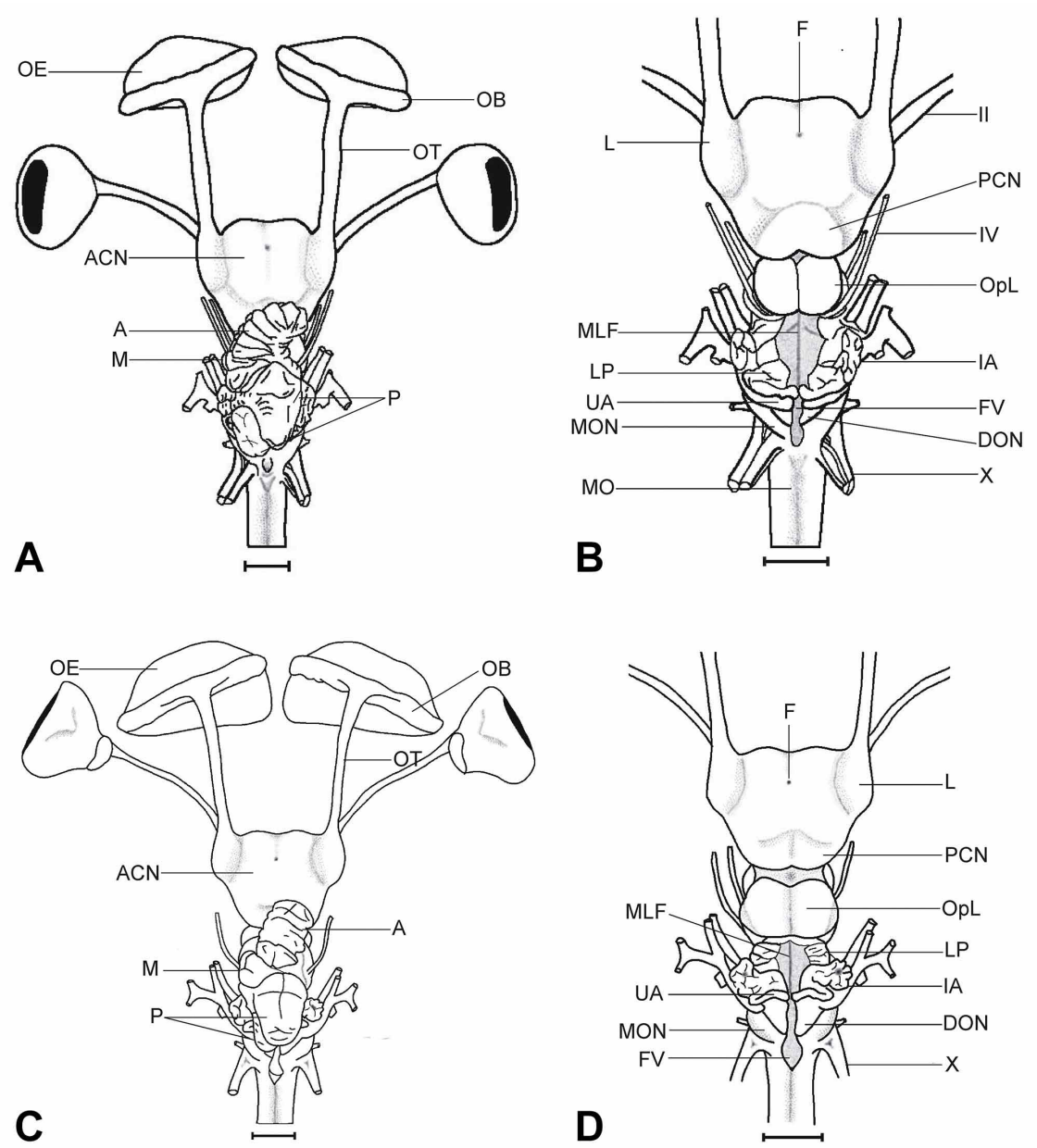

Fig. 1. Dorsal view of the encephalon: a) and b) Myliobatis californica, b) and c) Myliobatis longirostris. In c) and d) dorsal view when the cerebellum is removed. ACN, anterior central nucleus; A, anterior lobe of the cerebellum; DON, dorsal octavolateralis nucleus; F, fossa; FV, fourth ventricle; IA, inferior auricle; L, lateral pallium; LP, lateral peduncles; M, medium lobe of de cerebellum; MLF, medial longitudinal fasciculus; MO, medulla oblongata; MON, medial octavolateral nucleus; $\mathrm{P}$, posterior lobe of the cerebellum; $\mathrm{PCN}$, posterior central nucleus; OB, olfactory bulbs; OE, olfactory epithelium; OT, olfactory tracts; OpL, optic lobes; UA, upper auricle. Cranial nerves: II, optic; IV, trochlear; X, vagus. Scale $=10 \mathrm{~mm}$.
The brain of both Myliobatis species is quite similar. Therefore, a general description is presented, and the analysis will focus on the differences.

The Myliobatis' brain is relatively long and is inside the neurocranium cavity, which can be totally or partially occupied by it, depending on the organism size. Eyes are relatively large, and are in front of the telencephalon (Fig. $1 \mathrm{a}, \mathrm{c})$.

Telencephalon. The anterior region of the telencephalon is wider than the posterior one, and the posterior central nucleus is covered by the cerebellum. Olfactory tracts arise from the anterolateral part of the telencephalon, and runs anterolaterally to the ventral region, as can be observed in lateral view (Fig. 2). The tracts length increases with the organism size. Tracts are considerably thicker than the optic nerve (II), they are long and widen anteriorly, where are continued by the olfactory bulbs. The medial and lateral surface of the bulbs reaches the ventral region of the olfactory epithelium, as can be observed in lateral view (Fig. 2).

The telencephalon is relatively long. The anterior edge has three commissures, one central and two laterals. In the latter, the lateral pallium is quite developed, as can be observed in lateral view (Fig. 2 ). When the cerebellum is removed, it can be observed that the central nucleus of the telencephalon is split in one anterior and one posterior regions (Fig. $1 \mathrm{c}, \mathrm{f})$. The anterior division is larger than the posterior one, and has a fosseta on the medial line.

Diencephalon. In the cephalic region, the diencephalon is limited by the optic nerve (II). It extends ventrally in caudal position to the telencephalon, and is relatively small. In ventral view, the inferior 

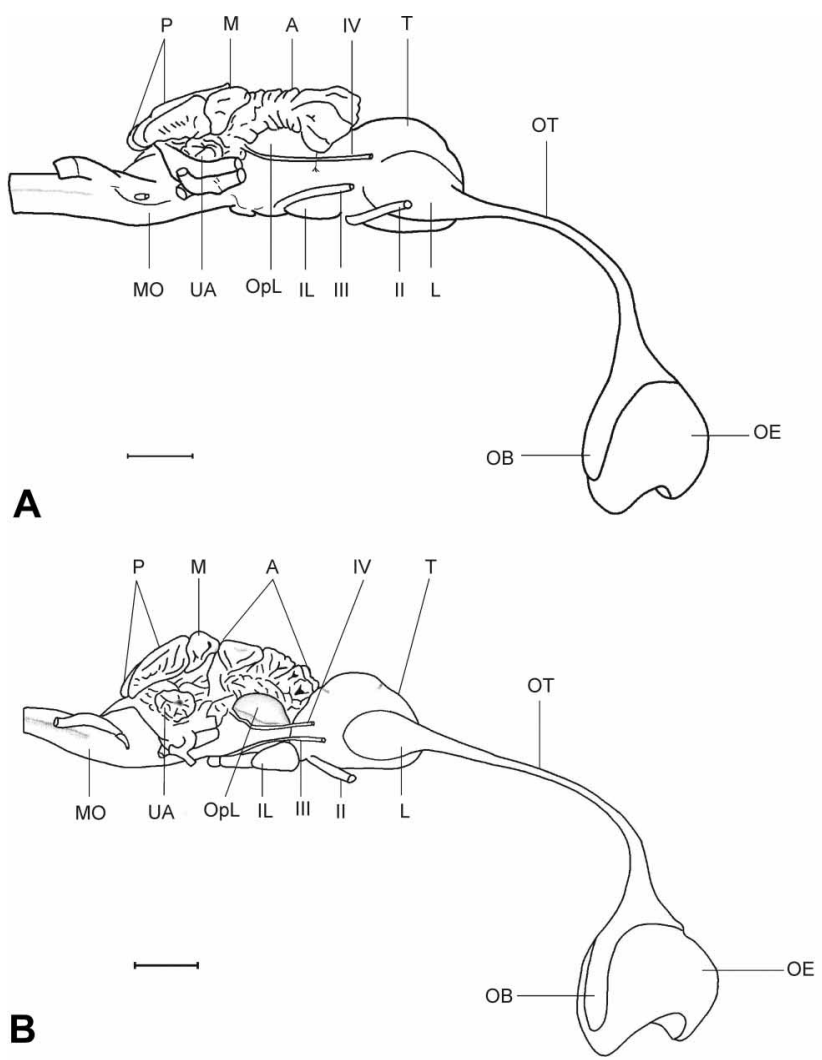

Fig. 2. Lateral view of the encephalon: a) Myliobatis californica, b) Myliobatis longirostris. A, anterior lobe of the cerebellum; IL, inferior lobes of the infundibulum; L, lateral pallium; $\mathrm{M}$, medium lobe of the cerebellum; MO, medulla oblongata; OB, olfactory bulbs; OE, olfactory epithelium; OT, olfactory tracts; OpL, optic lobes; P, posterior lobes of the cerebellum; T, telencephalon; UA, upper auricles. Cranial nerves: II optic; III, oculomotor; IV, trochlear. Scale $=10 \mathrm{~mm}$.

A
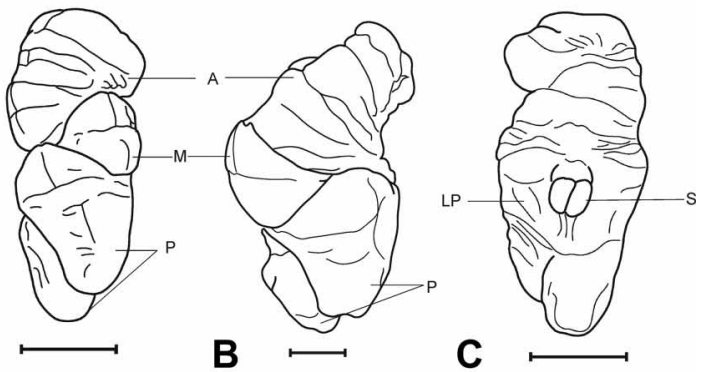

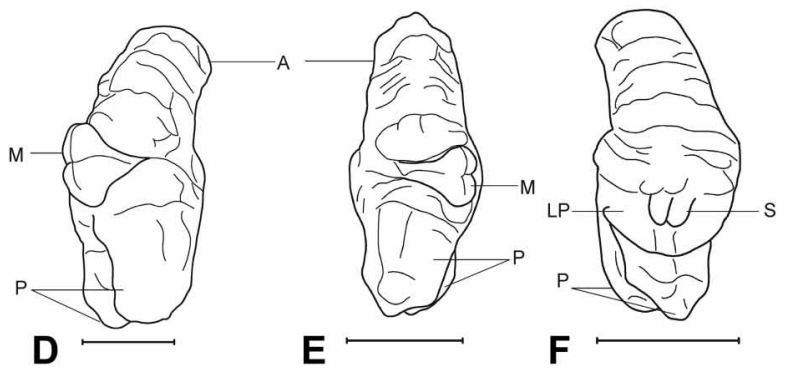

lobes of the infundibulum can be observed clearly defined, on both sides of the hypophysis. In M. californica, the inferior lobes are elongated and separated, while in $M$. longirostris they are rounded and located near the medium line (Fig. 4). The hypophysis is an elongated, three-lobed structure. The saccus vasculosus pair is located on both sides of the hypophysis, towards the posterior part of the infundibulum lobes.

Mesencephalon. The mesencephalon is partially covered by the cerebellum, and is wider than long. In the dorsal region, the mesencephalon is formed by the optic tectum; and in the ventral region by the optic tegmentum. The tectum forms the bigeminated lobes, which are separated by a sulcus. In M. longirostris these lobes are rounded, and in $\mathrm{M}$. californica are slightly oval (Fig. 1). In ventral view, a part of the optic tegmentum is visible, and on both sides of the posterior part of the hypophysis, a pair of protuberances, poorly developed can be observed, which are less evident in Myliobatis longirostris (Fig. 4).

Cerebellum. The cerebellum is formed by a long cerebellar body and the cerebellar auricles. The cerebellar body is on the fourth ventricle, extending rostrally on the mesencephalic tectum, and caudally on the inferior lip (auricle) of the cerebellum.

The cerebellar body is not symmetrical and is formed by four lobes, one anterior, one medium and two posterior one in dorsal and one in ventral position (Figs. 1a, c). The anterior lobe has the higher number of sulci, and is slightly smaller than the dorsal posterior lobe. The medium lobe is relatively small and can be found on the left or right side. Most sulci in the cerebellum are transversal, but a few longitudinal ca be observed, which are shallower (Fig. 3).

In the basal part of the body, on both sides of the fourth ventricle, the lateral peduncles can be found, linking the cerebellum with the median brain. These are rostrally limited by the posterior part of the mesencephalic tectum, and caudally by the upper lip. In the median region, on both sides of the lateral peduncles, a paired, rounded structure projects ventrally. This structure is the stem, which occupies the anterior part of the fourth ventricle (Figs. 3c, f).

Fig. 3. Cerebellum of Myliobatis californica: a) and b) dorsal view, c) ventral view. Myliobatis longirostris: d) and e) dorsal view, f) ventral view. A, anterior lobe of the cerebellum; LP, lateral peduncle; M, medium lobe of the cerebellum; $\mathrm{P}$, posterior lobe of the cerebellum; $\mathrm{S}$, steam. Scale $=10 \mathrm{~mm}$. 
The cerebellar auricles are clearly visible when the cerebellum is removed (Figs. 1b, d). On each side, they are formed by two leaves - one rostromedial superior and one caudolateral inferior. The first one is in anterior position, and the second in posterior position. In these species, in lateral view (Fig. 2), it can be observed that the anterior leaf is located in an inferior position, relative to
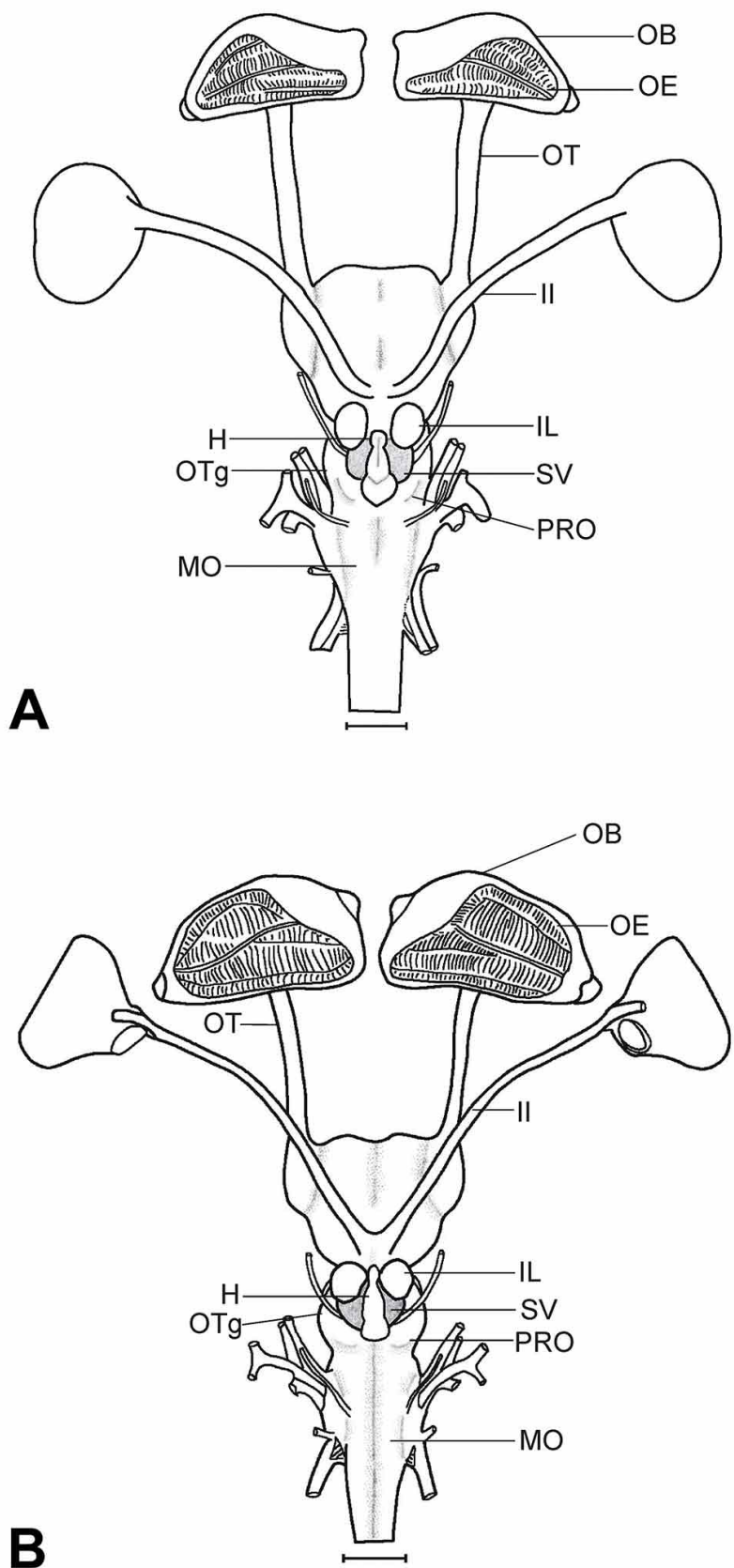

Fig. 4. Ventral view of the encephalon: a) Myliobatis californica, b) Myliobatis longirostris. H, hypophysis; IL, inferior lobes of the infundibulum; MO, medulla oblongata; $\mathrm{OB}$, olfactory bulbs; $\mathrm{OE}$, olfactory epithelium; OT, olfactory tracts; OTg, optic tegmentum; PRO, protuberance; $\mathrm{SV}$, saccus vasculosus. Cranial nerves: II, optic. Scale $=10 \mathrm{~mm}$. the posterior leaf. The inferior auricles are in a posterior position, as related to lateral peduncles, at level of nerve VIII; and the superior auricles are in an anterior position, relative to the octavolateralis area. The anterior auricles are ornamented, i. e., their profile is circumvoluted. The posterior auricles have a medial joint, forming an "inferior lip" which creates a bridge in the fourth ventricle. These auricles are smooth and thin, and are transversally arranged.

Medulla oblongata. The medulla oblongata is in the posterior region of the brain. In dorsal view, it is almost totally covered by the cerebellum. When the cerebellum and the posterior choroid plexus are removed, the relatively long, fourth ventricle can be observed. At its base, the medial longitudinal fascicle arises, which has a sulcus on its midline. The lateral peduncles of the cerebellum are at both sides of the ventricle, in the anterior region. On both sides, towards the ventricle posterior region, the developed dorsal octavolateralis nucleus can be observed. In lateral position relative to this nucleus, is the medial octavolateralis nucleus. In ventral view, the medulla oblongata has a sulcus in its middle region (Fig. 4).

Cranial nerves: The olfactory nerve (I) is inside the olfactory bulbs. The olfactory peduncles have been reported by several authors as the cranial pair I; however, they are formed by the secondary olfactory fibers, as reported by Smeets. The optic nerve (II), arises from the ventral part of the diencephalon, and is the boundary between the telencephalon and the diencephalon. On other vertebrate groups, the optic chiasma indicates the crossing over of optic nerves after leaving the cerebellum; in elasmobranchs, however, where this crossing over is absent, the term is used to indicate the origin of cranial pair II. (Fig. 5)

The oculomotor nerve (III) originates in the ventral part of the mesencephalon, in front of the protuberances; and the trochlear nerve (IV), arises from the dorsal region of the mesencephalon, in the posterolateral part of optic lobes. Both nerves run anteriorly. The abducens nerve (VI) is an extremely thin structure. In $M$. californica the origin is in the ventral region of the medulla oblongata, at the level of nerve VIII, and runs anteriorly towards the origin of nerve $\mathrm{V}$, to continue its trajectory on the ventral part of it. In M. longirostris, the abducens nerve follows a similar trajectory, but its origin is slightly posterior to the origin of nerve VIII.

Trigeminal (V), facial (VII) and acoustic (VIII) nerves, originate in the lateral wall of the medulla oblongata, and have and independent origin although they are very close. Pair VII is split in two main branches. After 

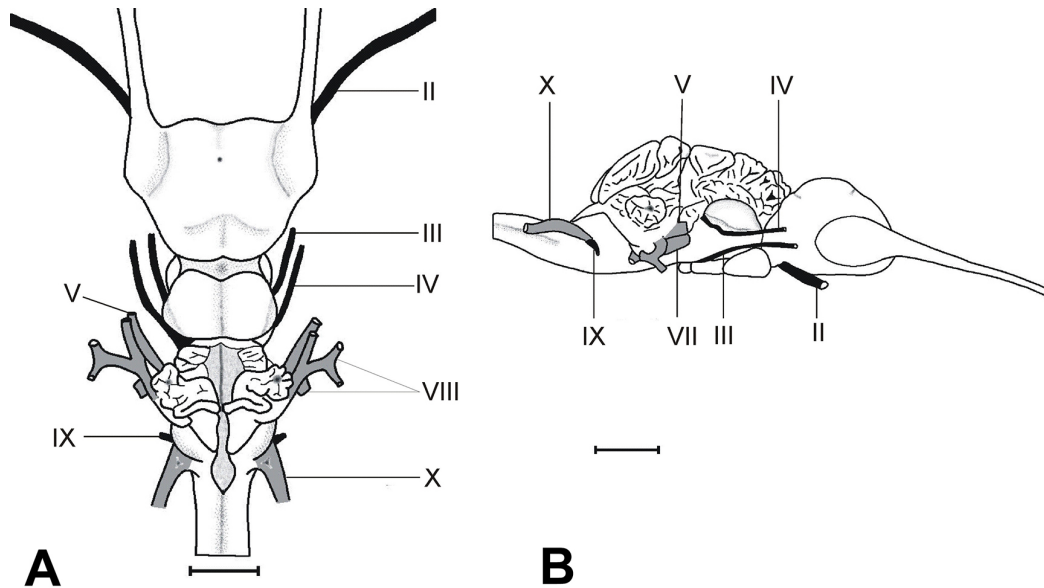

B

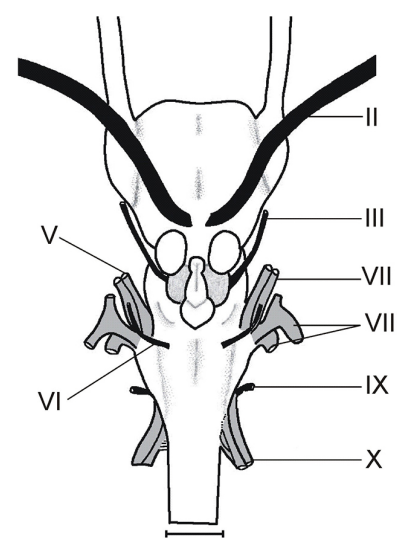

Fig. 5. Cranial nerves. Myliobatis longirostris: a) Dorsal view of the brain when the cerebellum is removed, b) lateral view c) ventral view. Myliobatis californica d) ventral view. II, optic; III, oculomotor; IV, trochlear; V, trigeminal; VI, abducens; VII, facial; VIII, acoustic; IX, glossopharyngeal; X, vagus. Scale $=10 \mathrm{~mm}$.

leaving the medulla oblongata, the glossopharyngeal nerve (IX) runs anteriorly, but after leaving the cranium, it changes direction and runs to the posterior region. The vague nerve $(\mathrm{X})$, originates in the lateral wall of the medulla oblongata, has several divisions and runs caudally.

\section{DISCUSSION}

In species of genus Myliobatis, the brain had distinctive characteristics as related to the neuroanatomy reported for other batoid genera. In M. californica and $M$. longirostris, the telencephalon is long and well developed. However, the central posterior nucleus is poorly developed, unlike most derived batoid species such as Mobula and Manta, where the posterior central nucleus is well developed (Ari), and considered to be a derived character. The olfactory tracts increase their length as the organism grows, as has been reported by Smeets, for other species. In Myliobatis, these structures have strongly migrated towards the ventral region, contrary to what has been reported for Diplobatis ommata (Montes Domínguez et al.), Urobatis jamaicensis (Walker \& Sherman), and other potamotrygonids (Fontanelle \& Carvalho), where the peduncles run either anteriorly or slightly bent towards the ventral region in the anterior part.

In different elasmobranch species, it has been described that the cerebellum is formed by three lobes, and the anterior lobe is the largest (Northcutt, 1989; Puzdrowski \& Leonard, 1992; Walker \& Sherman; Fontanelle \& Carvalho). However, in the two Myliobatis species in this study, four lobes were observed: one anterior, one medium and two posterior - the anterior being slightly smaller than the posterior one. In most derived species, such as Mobula and Manta, the cerebellum has a number of lobes (Ari). It has to be noted that neither the number of lobes nor their size have been reported for other species.

Another relevant characteristic in the Myliobatis brain is the medium lobe. This structure, besides being significantly smaller, as compared to species above, can be on the right or the left side (Fig. 3). Variations in the orientation of the cerebellar lobes have been reported only for Dasyatis sabina (Puzdrowski \& Leonard).

Cranial pairs VII and VIII, have an independent origin, as reported by Montes Domínguez et al. for Diplobatis ommata, and oppose to what was reported by Walker \& Sherman for Urobatis jamaicensis. These authors state that nerves VII and VIII have a common origin. It should be noted that in dorsal view, it is observed that nerve VIII is on nerve VII and apparently, these have a common origin; but it actually originates at a point slightly posterior, right below nerve VII. This arrangement could lead to the wrong conclusion that they have a common origin. 
Based on the above characteristics, it can be stated that the brains of $M$. californica and $M$. longirostris are quite similar, with the following significant differences: 1) in $M$. longirostris, the peduncles migration towards the ventral region is stronger than in $M$. californica. 2) In $M$. californica, the cerebellum has a larger number of sulci. 3) The infundibulum lobes are more separated in M. californica. 4) In M. californica, nerve VI arises at the level of nerve VIII, while in M. longirostris it originates posteriorly to nerve VIII.

Myliobatis, together with Aetomylaeus form the sister group of more derived myliobatoids (Naylor et al., 2016). However, and despite its brain having characteristics exclusive to this genus, it is relatively simple in contrast to what has been reported for more derived myliobatoids, such as Mobula and Manta.

MONTES-DOMÍNGUEZ, H. M.; AYALA-PÉREZ, L. A.; CASTILLO-RIVERA, M. A.; GONZÁLEZ-ISÁIS, M. \& REYNOSO, V. H. Neuroanatomía de dos especies del género Myliobatis (Chondrichthyes: Myliobatoidea). Int. J. Morphol., 38(2):499-504, 2020.

RESUMEN: Diversos estudios sobre la neuroanatomía de los elasmobranquios han demostrado que el cerebro es más complejo de lo que se pensaba y presenta considerables variaciones tanto intra como interespecíficas. El objetivo de este trabajo fue realizar un estudio de neuroanatomía comparada del encéfalo de dos especies del género Myliobatis. Se utilizaron un total de 16 organismos de Myliobatis californica y Myliobatis longirostris, los cuales fueron colectados en las costas de Bahía Kino, Son., México. El cerebro de Myliobatis tiene un telencéfalo largo, el núcleo central posterior está poco desarrollado; el cerebelo es asimétrico, presenta surcos que en su mayoría están orientados transversalmente, con cuatro lóbulos (anterior, medio y dos posteriores), condición que no ha sido reportada para otra especie. Se observó que, aunque $M$. californica y $M$. longirostris presentan una morfología similar existen ciertas diferencias. En ambas especies presentan una foliación moderada; sin embargo, en M. californica se observan más surcos. En el diencéfalo de $M$. californica se observa que los lóbulos del infundíbulo son ovalados y están separados, mientras que en $M$. longirostris son redondeados y se encuentran próximos a la línea media. Es importante señalar que, pese a que Myliobatis pertenece al grupo de batoideos más derivado, su cerebro es considerablemente menos complejo de lo que se ha reportado para las especies de miliobatoideos más derivadas.

PALABRAS CLAVE: Elasmobranchii; Myliobatis; Cerebro; Telencéfalo; Cerebelo.

\section{REFERENCES}

Ari, C. Encephalization and brain organization of Mobulid rays (Myliobatiformes, Elasmobranchii) with ecological perspectives. Open Anat. J., 3:1-13, 2011.
Compagno, L. J. V. Alternative life-history styles of cartilaginous fishes in time and space. Environ. Biol. Fish., 28:33-75, 1990.

Fontanelle, J. P. \& Carvalho, M. R. Systematic implications of brain morphology in Potamotrygonidae (Chondrichthyes: Myliobatiformes). J. Morphol., 277(2):252-63, 2016.

Hoffman, M. H. Nervous System. In: Hamlet, W. C. (Ed.). Sharks, Skates, and Rays: The Biology of Elasmobranch Fishes. Baltimore, Johns Hopkins University Press, 1999.

Kobelkowsky, A. Comparative anatomy of the neurocranium and encephalon of the butterfly ray, Gymnura micrura (Batoidea: Gymnuridae). Int. J. Morphol., 35(2):644-50, 2017.

Lisney, T. J. \& Collin, S. P. Brain morphology in large pelagic fishes: a comparison between sharks and teleosts. J. Fish Biol., 68(2):532-54, 2006.

Lisney, T. J.; Bennett, M. B. \& Collin, S. P. Volumetric analysis of sensory brain areas indicates ontogenetic shifts in the relative importance of sensory systems in elasmobranchs. Raffles Bull. Zool., 14:7-15, 2007.

Lisney, T. J.; Yopak, K. E.; Camilieri-Asch, V. \& Collin, S. P. Ontogenetic shifts in brain organization in the bluespotted stingray Neotrygon kuhlii (Chondrichthyes: Dasyatidae). Brain Behav. Evol., 89(2):68-83, 2017.

Montes Domínguez, H. M.; López Bárcenas, R. \& González Isáis, M. Morphological study of the brain and cranial nerves of Diplobatis ommata (Elasmobranchii: Narcinidae). Int. J. Morphol., 32(4):1152-5, 2014.

Naylor, G. J. P.; Yang, L.; Corrigan, S. \& de Carvalho, M. R. Phylogeny and Classification of rays. In: Last, P. R.; White, W. T.; de Carvalho, M. R.; Séret, B.; Stehmann, M. F. W. \& Naylor, G. J. P. (Eds.). Rays of the World. Sidney, Csiro Publishing, 2016.

Nelson, J. S.; Grande, T. C. \& Wilson, M. V. H. Fishes of the World. $5^{\text {th }}$ ed. Hoboken, John Wiley \& Sons, 2016.

Northcutt, R. G. Brain Organization in the Cartilaginous Fishes. In: Hodgson, E. S. \& Mathewson R. F. (Eds.). Sensory Biology of Sharks, Skates, and Rays. Arlington, Office of Naval Research, 1978.

Northcutt, R. G. Brain variation and phylogenetic trends in elasmobranch fishes. J. Exp. Zool. Suppl., 2:83-100, 1989.

Northcutt, R. G. Elasmobranch central nervous system organization and its possible evolutionary significance. Am. Zool., 17(2):411-29, 1977.

Puzdrowski, R. L. \& Leonard, R. B. Variations in cerebellar morphology of the Atlantic stingray, Dasyatis sabina. Neurosci. Lett., 135(2):196200, 1992.

Smeets, W. J. A. J. Cartilaginous Fishes. In: Nieuwenhuys, R. \& Roberts, B. L. (Eds.). The Central Nervous System of Vertebrates. Berlin, Springer-Verlag, 1998.

Walker, K. B. \& Sherman, L. R. Gross brain morphology in the yellow stingray, Urobatis jamaicensis. Florida Sci., 64(4):246-9, 2001.

White, W. T. \& Last, P. R. Eagle Rays. Family Myliobatidae. In: Last, P. R.; White, W. T.; de Carvalho, M. R.; Séret, B.; Stehmann, M. F. W. \& Naylor, G. J. P. (Eds.). Rays of the World. Sidney, Csiro Publishing, 2016.

Corresponding autor:

Héctor Marcos Montes Domínguez

FES Iztacala, UNAM

Av. de los Barrios $N^{\circ} 1$

Los Reyes Iztacala

Tlalnepantla de Baz

MÉXICO

Email: goritec@unam.mx

Received : 21-09-2019

Accepted : 17-10-2019 